\title{
Triptycene End-Capped Quinoxalinophenanthrophenazines with Aromatic Substituents - Synthesis, Characterization, and Single-Crystal Structure Analysis
}

\author{
Lucas Ueberricke ${ }^{a}$ \\ Sonja Wieland ${ }^{a}$ \\ Frank Rominger ${ }^{a}$ \\ Michael Mastalerz*a (i) \\ ${ }^{a}$ Organisch-Chemisches Institut, Ruprecht-Karls-Universität Heidelberg, Im \\ Neuenheimer Feld 270, 69120 Heidelberg, Germany, \\ Michael.mastalerz@oci.uni-heidelberg.de
}

Received: 03.07.2019

Accepted after revision: 26.08.2019

DOI: 10.1055/s-0039-1700847; Art ID: om-19-0005-oa

License terms: CC)

(c) 2019. The Author(s). This is an open access article published by Thieme under the terms of the Creative Commons Attribution-NonDerivative-NonCommercial-License, permitting copying and reproduction so long as the original work is given appropriate credit. Contents may not be used for commercial purposes, or adapted, remixed, transformed or built upon. (https://creativecommons.org/licenses/by-nc-nd/4.0/).

Abstract In a previous study, we found that one-fold triptycene endcapped quinoxalinophenanthrophenazines (QPPs) arrange in crystals preferably in a coplanar fashion providing high overlap of the m-planes. Thus, resulting in high calculated charge transfer integrals. Most interestingly, this motif was observed for a variety of QPPs derivatives, independently of the nature of their peripheral substituents, e.g. bromide, methoxy, cyano, or triisopropylsilylethynyl groups, and of the crystallization conditions. Here, we describe the synthesis of another small series of three QPPs containing different aromatic substituents at the same position to get an insight, whether these aromatic substituents disturb the otherwise preferred $\pi$ stacking of the QPP planes.

Key words triptycenes, quinoxalinophenanthrophenazines, N-heterocycles, polycyclic aromatic compounds

\section{Introduction}

The property of molecular materials is strongly related to the assembly of defined molecular precursors in the solid state. Finding the "best" polymorph is challenging and predicting it from scratch is the holy grail of today's crystal engineering. ${ }^{1-5}$ There are several structural motifs that direct packing more efficiently than others, such as highly directive hydrogen ${ }^{6}$ or halogen bonding ${ }^{7,8}$ versus less or nondirecting $\pi$-stacking ${ }^{9-11}$ or dispersion interactions. ${ }^{12}$ In the field of organic electronics, the orientation and distances
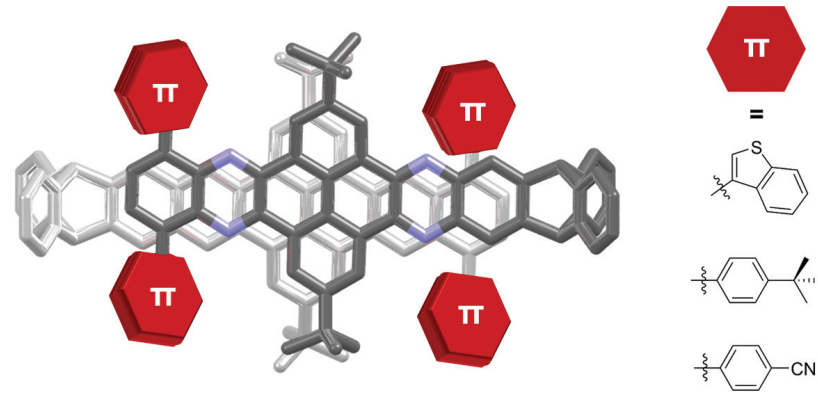

of aromatic $\pi$-planes are crucial for achieving sufficient charge transport and small changes of the arrangement geometries of extended $\pi$-systems can have a significant impact (negative as well as positive) on the performance of such organic electronic devices. ${ }^{13,14}$ As mentioned already, $\pi$-stacking is unfortunately less directional than other supramolecular motifs and therefore ideal arrangements are more difficult to achieve. ${ }^{9-11}$

During our initial work on organic molecules with intrinsic microporosities, ${ }^{15-22}$ we observed a hexagonal packing of $D_{3 \mathrm{~h}}$-symmetric triptycene-based large quinoxalinophenanthrophenazines (QPPs) via an unusual strong $\pi-\pi$ interaction of the QPP blades with those of adjacent QPP molecules. ${ }^{23}$ This packing motif could only be broken by triptycene-end-capping. ${ }^{19} \mathrm{~A}$ first systematic study of different QPPs with and without triptycenylene endcaps as well as with and without central tert-butyl groups revealed that one triptycene endcap has a supportive directing effect of the two $\pi$-planes and additionally increases the energy of interaction. This was supported by SAPT-DFT calculations. ${ }^{23}$ To our delight, we found the same dimer formation also for $D_{3 \mathrm{~h}}$ symmetric QPP with a central triptycene core bearing three $\pi$ planes that contain triisopropylsilylethynyl groups at the peripheral phenylene rings. ${ }^{22}$ This encouraged us to further systematically study the influence of smaller substituents such as bromide, methoxy, or cyano at the peripheral rings on the packing motif. Again, the dimer formation was observed for all derivatives under specific crystallization conditions (e.g. slow evaporation of solvent, by vapor diffusion of an antisolvent, or thermal crystallization). Since the transfer integrals of electron as well as hole transport were with 193 and $145 \mathrm{meV}$, exceptionally high for this type of $\pi$-stacked dimer, ${ }^{24}$ we became interested in understanding how far the structural deviation can be taken to establish it as a crystal engineering synthon.

Here, we present another small series of QPPs, which contain additional aromatic substituents at the peripheral 
phenylene units, because they could in principle affect the dimer formation by competing $\pi-\pi$ interactions.

\section{Results and Discussion}

\section{Synthesis}

For the synthesis of QPP derivatives with larger substituents, two different approaches were used (Scheme 1). First, the previously reported QPP-Br ${ }^{24}$ was reacted with 3-benzothiophenyl boronic pinacol ester via the SuzukiMiyaura cross-coupling reaction $\left(\mathrm{Pd}_{2}(\mathrm{dba})_{3} / \mathrm{P}(0 \text {-tol })_{3} / \mathrm{K}_{3} \mathrm{PO}_{4}\right.$ in $\mathrm{H}_{2} \mathrm{O} /$ toluene/1,4-dioxane mixture at $\left.60{ }^{\circ} \mathrm{C}\right)^{25}$ to give $\mathbf{Q P P}$ BTh in $14 \%$ yield. After ending the reaction, the solution contained mainly starting material along with some traces of one-fold coupled and one-fold dehydrobrominated product, which were not further purified. Most likely, the poor reactivity is attributed to the low solubility of QPP-Br as this does not provide the required concentration for the Suzuki-Miyaura cross-coupling reaction, which is typically carried out at substrate concentrations of around 0.5 $\mathrm{mol} / \mathrm{L}{ }^{26}$ To overcome this issue, the other two derivatives were synthesized by condensation of diketone $2^{23}$ with the respective phenylene diamines $\mathbf{1 a}$ and $\mathbf{1 b}{ }^{27-29}$ This proved to be a better approach, giving QPP-Pht ${ }^{t} \mathbf{B u}$ in $90 \%$ yield. For QPP-PhCN the isolated yield was 37\% despite a similarly high conversion detected in the ${ }^{1} \mathrm{H}$ NMR spectrum of the crude product. To remove excess of unreacted diamine, which, in contrast to QPP-Pht ${ }^{\mathbf{B}} \mathbf{B u}$, could not be removed by simply washing with methanol, an additional recrystalliza- tion step was necessary. All derivatives were completely characterized by ${ }^{1} \mathrm{H}$ and ${ }^{13} \mathrm{C}$ NMR spectroscopy, mass spectrometry, and IR.

Figure 1 shows the ${ }^{1} \mathrm{H}$ NMR spectra of the three compounds. In the case of QPP-BTh the benzothiophene units can be identified by a singlet at $\delta=8.21 \mathrm{ppm}$ for the $\alpha$-proton $\mathrm{H}^{\mathrm{a}}$ of the five-membered ring, two triplets for the protons $\mathrm{H}^{\mathrm{c}}$ and $\mathrm{H}^{\mathrm{d}}$ at $\delta=7.37$ and $7.46 \mathrm{ppm}$, and two doublets for $\mathrm{H}^{\mathrm{b}}$ and $\mathrm{H}^{\mathrm{e}}$ at $\delta=7.90$ and $8.08 \mathrm{ppm}$, respectively. The signals $\mathrm{H}^{\mathrm{a}}$ and $\mathrm{H}^{\mathrm{b}}$ of the other two compounds can be identified at $\delta=8.06$ and $7.69 \mathrm{ppm}$ for

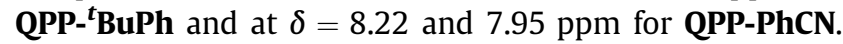
The signal of the additional tert-butyl group of QPP- ${ }^{t} \mathbf{B u P h}$ is found at $\delta=1.50 \mathrm{ppm}$. The signals of the bridgehead protons of triptycene $\mathrm{H}^{\mathrm{A}}$ appear at $\delta=5.73 \mathrm{ppm}$ and those of the protons of the triptycene phenylene blades at $\delta=8.36 \mathrm{ppm}\left(\mathrm{H}^{\mathrm{D}}\right), \delta=7.10 \mathrm{ppm}\left(\mathrm{H}^{\mathrm{C}}\right)$, and $\delta=7.51 \mathrm{ppm}$ $\left(\mathrm{H}^{\mathrm{B}}\right)$ for all three compounds. It is noteworthy that the protons closest located to the substituents $H^{G}$ are hardly affected by the substituents and shift only within a narrow range of $\delta=8.08-8.01 \mathrm{ppm}$. Instead, the pyrene doublets $\mathrm{H}^{\mathrm{E}}$ and $\mathrm{H}^{\mathrm{F}}$ are more affected and strong shifts, for example from $\delta=9.15 \mathrm{ppm}$ for QPP-BTh to $\delta=9.59 \mathrm{ppm}$ for QPP- ${ }^{\text {B }} \mathbf{B u P h}$, can be observed.

\section{Optoelectronic Properties in Solution}

All QPPs have been studied by UV/vis and fluorescence spectroscopy in chloroform (Figure 2). All spectra show similar absorption peaks at $\sim 420,400$, and $336 \mathrm{~nm}$, which

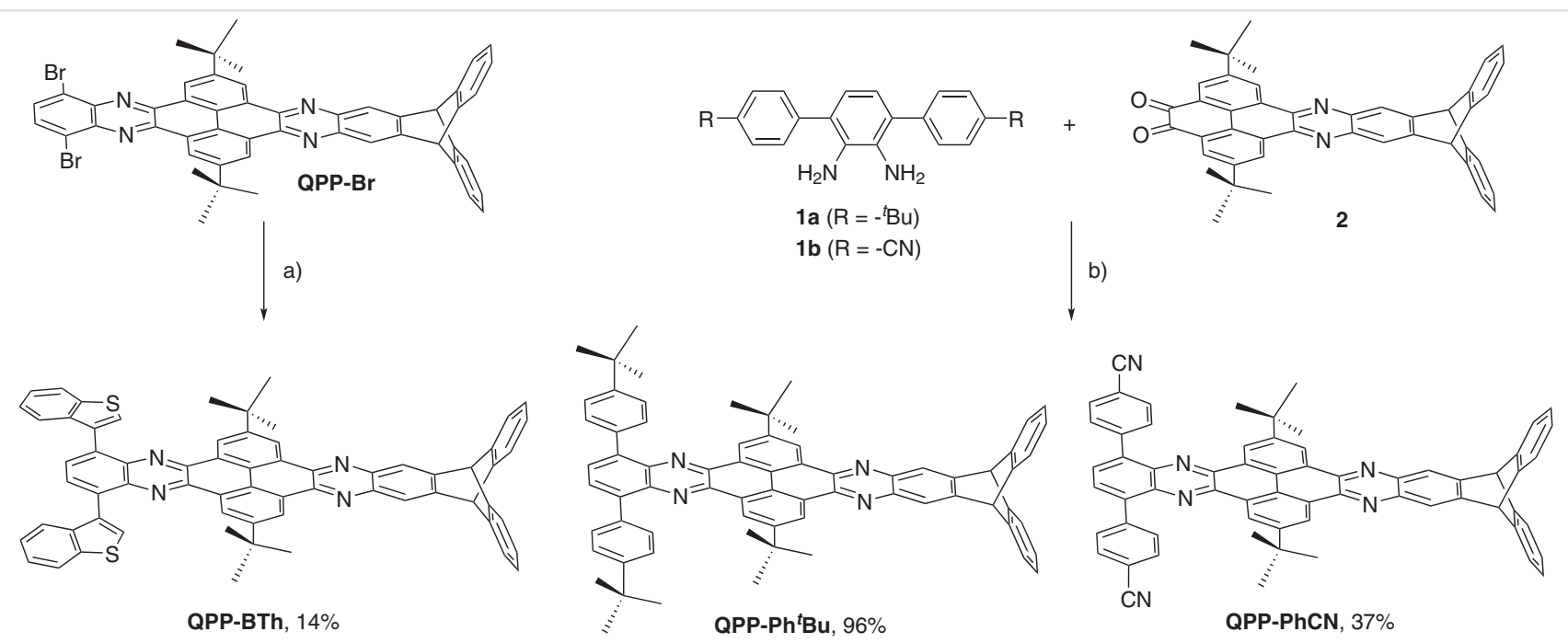

Scheme 1 Synthesis of QPP-BTh, QPP-Ph ${ }^{t} \mathbf{B u}$, and QPP-PhCN. (a) 3-Benzothiophenyl pinacol boronic ester, 3 mol-\% $\mathrm{Pd}_{2}(\mathrm{dba})_{3}, 25 \mathrm{~mol}-\% \mathrm{P}^{\circ}(\mathrm{o}-\mathrm{tol})_{3}$, $\mathrm{K}_{3} \mathrm{PO}_{4}, \mathrm{H}_{2} \mathrm{O}$, toluene, 1,4-dioxane, $\mathrm{Ar}, 60^{\circ} \mathrm{C}, 17 \mathrm{~h}$; (b) $\mathrm{CHCl}_{3}, \mathrm{AcOH}, 70{ }^{\circ} \mathrm{C}, 16 \mathrm{~h}$. 


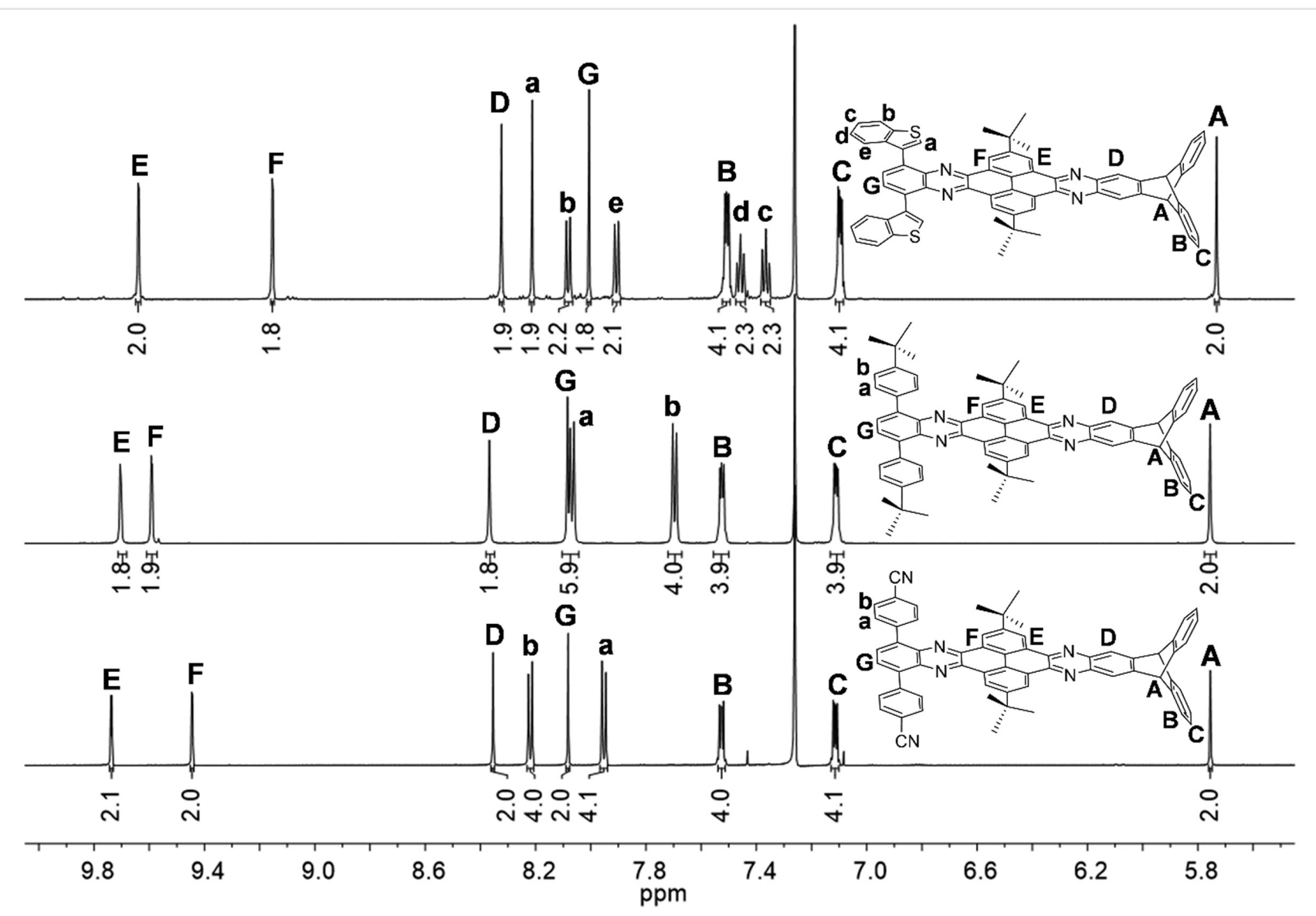

Figure $1{ }^{1} \mathrm{H}$ NMR spectra (600 MHz, $\mathrm{CDCl}_{3}$ ) of QPP-BTh, $\mathbf{Q P P}-\mathbf{P h}^{t} \mathbf{B u}$, and QPP-PhCN (from top to bottom).

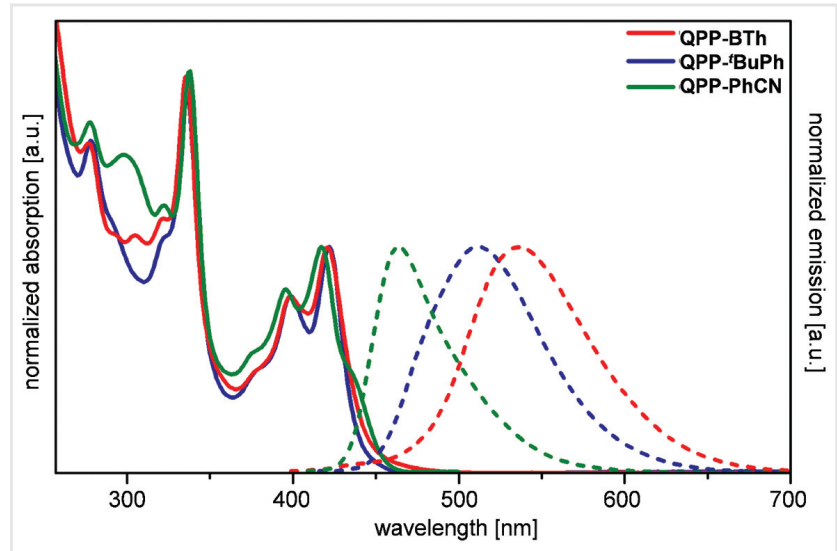

Figure 2 UV/vis absorption (continuous line) and normalized emission spectra (dashed line) of QPP-BTh, QPP-Ph ${ }^{t}$ Bu, and QPP-PhCN in $\mathrm{CHCl}_{3}$ $\left(1 \times 10^{-6} \mathrm{~mol} / \mathrm{L}\right)$ at room temperature.

can be assigned to $n-\pi^{*}$ and $\pi-\pi^{*}$ transitions..$^{30}$ QPP-PhCN exhibits an additional bathochromically shifted shoulder at $438 \mathrm{~nm}$. The emission maxima shift from $\lambda_{\mathrm{em}}=464 \mathrm{~nm}$ for QPP-PhCN, to over $512 \mathrm{~nm}$ for $\mathbf{Q P P}-\mathbf{P h}^{\mathbf{t}} \mathbf{B u}$, and to $536 \mathrm{~nm}$ for QPP-BTh. This corresponds to Stokes shifts of 2,429, 4,166 , and $5,096 \mathrm{~cm}^{-1}$, indicating an increase of reorganization energy for the transition from the ground state to the first excited state. The quantum yields vary within a range of $20-33 \%$ in chloroform solution.

The electronic properties were studied by cyclic voltammetry (CV) in o-DCB (Figure 3). For QPP-BTh and QPP-Ph ${ }^{t} \mathbf{B u}$ the first reduction potentials are almost equal $\left(E^{\text {red,1 }}=\right.$ $-1.9 \mathrm{eV}$ vs. $E^{\mathrm{red}, 1}=-2.0 \mathrm{eV}$ ). The second reduction potentials are the same for both compounds $\left(E^{\text {red,2 }}=-2.2 \mathrm{eV}\right)$. The electron-deficient QPP-PhCN exhibits lower reduction potentials at $E^{\text {red,1 }}=-1.8 \mathrm{eV}$ and $E^{\text {red,2 }}=-2.1 \mathrm{eV}$. A third potential was found at $E^{\text {red, } 3}=-2.2 \mathrm{eV}$. What was observed is in agreement with previously published results on QPP-CN, which also exhibited three reduction potentials; supporting the assumption that the third potential is correlated with the reduction of the cyano groups. ${ }^{24}$ According to the often used equation $E_{\mathrm{LUMO}, \mathrm{CV}}=-\left(E_{\mathrm{red}, 1}+4.8\right) \mathrm{eV},{ }^{31}$ the LUMO levels were estimated to be between $E_{\mathrm{LUMO}}=-2.8 \mathrm{eV}$ and $E_{\mathrm{LUMO}}=-3.0 \mathrm{eV}$. Since no oxidation potentials could be determined, HOMO levels $\left(E_{\text {Hомо }}=-5.7 \mathrm{eV}\right.$ or $\left.-5.6 \mathrm{eV}\right)$ were estimated by subtracting the energies of the optical 


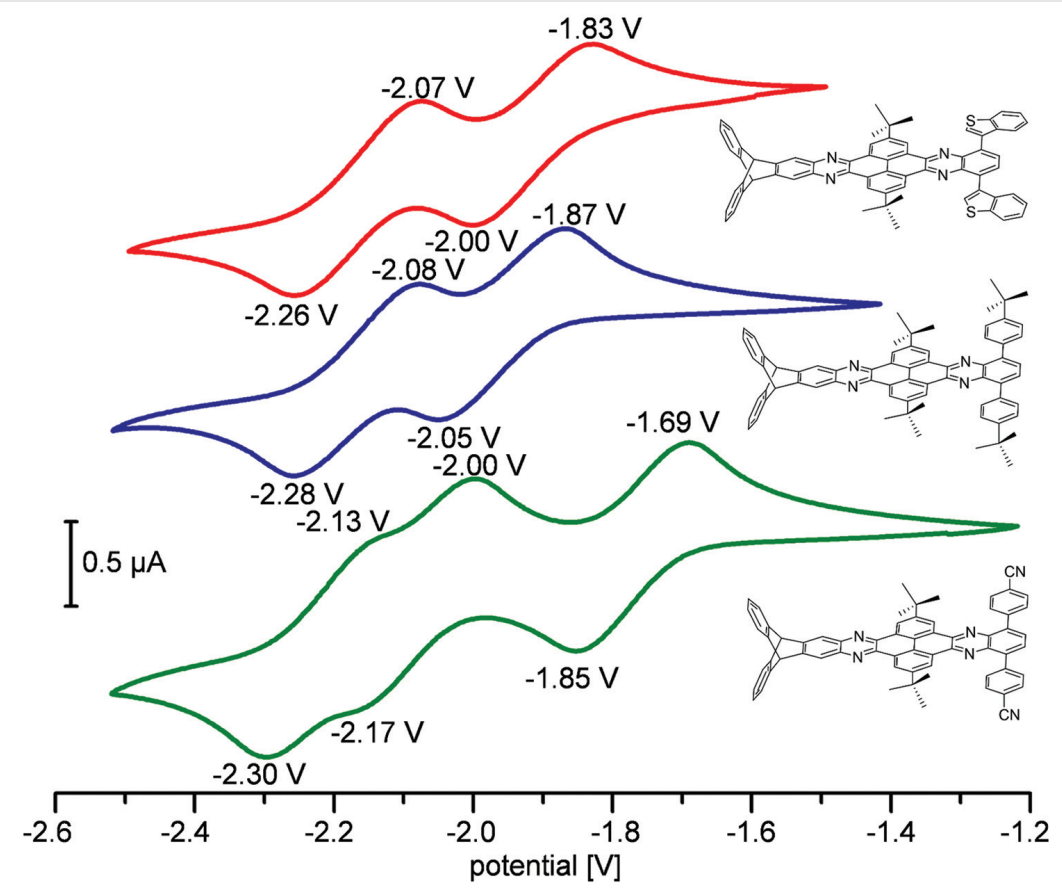

Figure 3 Cyclic voltammograms of QPP-BTh, QPP-Ph ${ }^{t} B u$, and QPP-PhCN $\left[0-D C B, n B u_{4} N^{N P F} F_{6}(0.1 \mathrm{M})\right]$, measured at room temperature with a Pt electrode $\left(0.78 \mathrm{~mm}^{2}\right)$ and $\mathrm{Fc} / \mathrm{Fc}^{+}$as an internal reference (scanning speed: $50 \mathrm{mV} / \mathrm{s}$ ).

band gap obtained from UV/vis measurements from the calculated LUMO energies. However, this method is somewhat misleading as it ignores the exciton-binding energy and this explains potential deviations from the calculated HOMO levels (see below). ${ }^{32}$
By quantum chemical calculations (DFT-B3LYP/6$\left.311++\mathrm{G}^{* *}\right)$, the molecular frontier orbitals were calculated (Figure 4). For QPP-BTh and QPP-Ph ${ }^{\mathbf{B}} \mathbf{B u}$, the HOMOs are mainly located on the para-substituted peripheral phenylene part distributed over both aromatic substituents. The

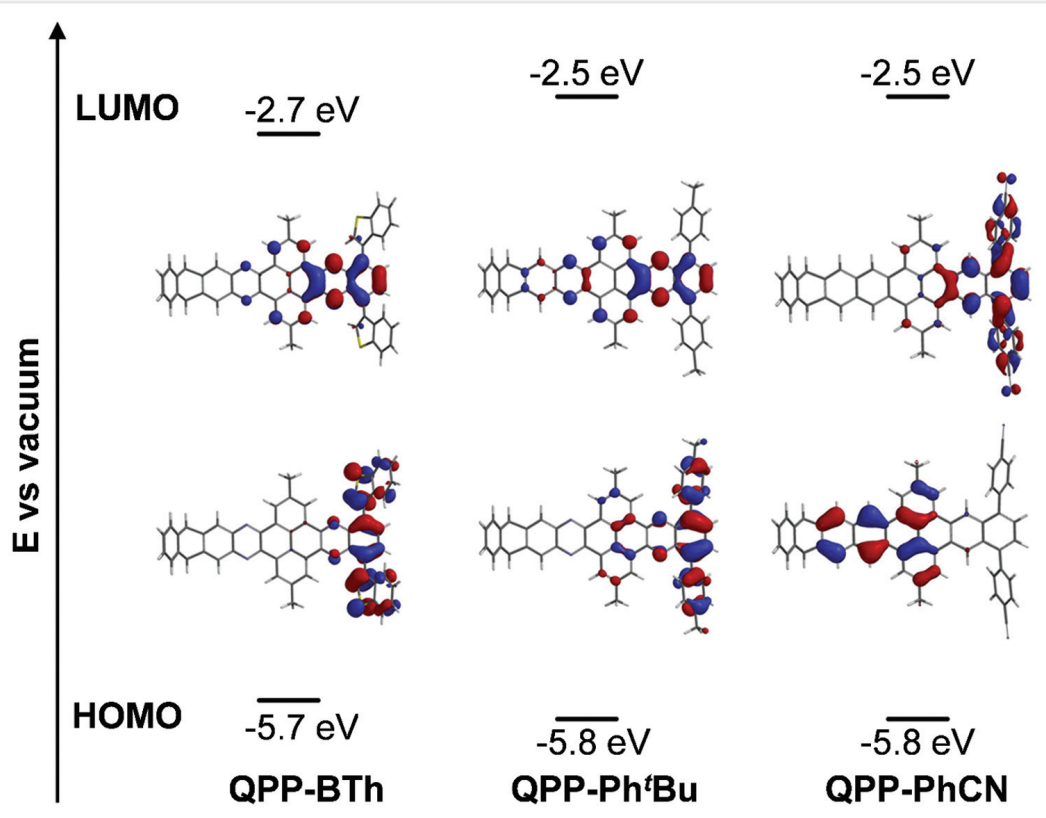

Figure 4 HOMO-LUMO diagram of QPP-BTh, QPP-Pht Bu, and QPP-PhCN (calculated using DFT-B3LYP: 6-311 + + ${ }^{* *}$ ). 
Table 1 Optoelectronic and electrochemical properties of QPP-BTh, QPP-Ph ${ }^{t} \mathrm{Bu}$, and QPP-PhCN

\begin{tabular}{|c|c|c|c|c|c|c|c|c|c|c|c|c|c|c|}
\hline Compd & $\begin{array}{l}\lambda_{\mathrm{abs}}^{\mathrm{a}, \mathrm{b}} \\
{[\mathrm{nm}]}\end{array}$ & $\begin{array}{l}\lambda_{\text {onset }} \\
{[\mathrm{nm}]}\end{array}$ & $\begin{array}{l}\lambda_{\mathrm{em}}{ }^{\mathrm{a}} \\
\left(\lambda_{\mathrm{ex}}\right)\end{array}$ & $\begin{array}{l}\text { Stokes shift } \tilde{v} \\
{\left[\mathrm{~cm}^{-1}\right]}\end{array}$ & $\begin{array}{l}\Phi^{\mathrm{a}} \\
{[\%]}\end{array}$ & $\begin{array}{l}E_{g(\text { opt t }}{ }^{c} \\
{[\mathrm{eV}]}\end{array}$ & $\begin{array}{l}E^{\mathrm{red} 1 \mathrm{~d}} \\
{[\mathrm{~V}]}\end{array}$ & $\begin{array}{l}E^{\mathrm{red} 2 \mathrm{~d}} \\
{[\mathrm{~V}]}\end{array}$ & $\begin{array}{l}E^{\text {red3d }} \\
{[\mathrm{V}]}\end{array}$ & $\begin{array}{l}E_{\text {LUMO }}{ }^{\mathrm{e}} \\
{[\mathrm{eV}]}\end{array}$ & $\begin{array}{l}E_{\text {Номо }}{ }^{\mathrm{e}} \\
{[\mathrm{eV}]}\end{array}$ & $\begin{array}{l}E_{1 \mathrm{LMMO}}^{\mathrm{DFTf}} \\
{[\mathrm{eV}]}\end{array}$ & $\begin{array}{l}E_{\mathrm{HOMO}}^{\text {DFTf }} \\
{[\mathrm{eV}]}\end{array}$ & $\begin{array}{l}E_{\mathrm{g}}^{\mathrm{DFTf}} \\
{[\mathrm{eV}]}\end{array}$ \\
\hline QPP-BTh & 421 & 443 & $\begin{array}{l}536 \\
(401)\end{array}$ & 5,096 & 33 & 2.8 & -1.9 & -2.2 & - & -2.9 & -5.7 & -2.7 & -5.7 & 3.0 \\
\hline QPP-Ph ${ }^{t} \mathrm{Bu}$ & 422 & 443 & $\begin{array}{l}512 \\
(402)\end{array}$ & 4,166 & 30 & 2.8 & -2.0 & -2.2 & - & -2.8 & -5.6 & -2.5 & -5.8 & 3.3 \\
\hline QPP-PhCN & $\begin{array}{l}417 \\
438^{\text {sh }}\end{array}$ & 460 & $\begin{array}{l}464 \\
(387)\end{array}$ & 2,429 & 21 & 2.7 & -1.8 & -2.1 & -2.2 & -3.0 & 5.7 & -2.5 & -5.8 & 3.3 \\
\hline
\end{tabular}

a Measured in $\mathrm{CHCl}_{3}$ at rt.

bAbsorption maximum at the longest wavelength; sh, shoulder.

${ }^{\mathrm{c}}$ Estimated from onset.

${ }^{\mathrm{d} C y c l i c}$ voltammogram measured in o-DCB with a Pt electrode and $n \mathrm{Bu}_{4} \mathrm{NPF}_{6}$ as electrolyte. Scan speed: $50 \mathrm{mV} / \mathrm{s}$; ferrocene/ferrocenium (Fc/Fc ${ }^{+}$) was used as internal

${ }^{\mathrm{e}} E_{\mathrm{LUMO}}=-\left(E^{\mathrm{red} 1}+4.8\right) \mathrm{eV} ; E_{\mathrm{g}(\mathrm{opt})}=\frac{1242}{\lambda_{\text {onset }}} ; E_{\mathrm{HOMO}}=E_{\mathrm{LUMO}}-E_{\mathrm{g}(\mathrm{opt})}$.

fObtained from quantum-chemical calculations using DFT-B3LYP/6-311 + + $\mathrm{G}^{* *}$

LUMOs instead are located more on the QPP backbone. In the case of QPP-PhCN the situation is reversed. The HOMO is delocalized over the pyrene and triptycene units of the extended QPP system and not found on the peripheral disubstituted phenylene ring of the QPP. The corresponding LUMO is distributed on the terphenyl unit and most interestingly orbital coefficients of the LUMO are not shared by atom coordinates of the HOMO coefficients, making this compound a type of cruciform. ${ }^{33-36}$ The energies of both LUMOs $(-2.7$ to $-2.5 \mathrm{eV})$ and HOMOs $(-5.7$ to $-5.8 \mathrm{eV}$ ) of all three compounds are rather similar and approximately the same as for the parent QPP suggesting a negligible effect of the substituents on these energy levels. ${ }^{24}$ The optoelectronic properties are summarized in Table 1.

\section{Optical Properties in the Solid State}

To study the solid-state optical properties, thin films of all three compounds were fabricated by spin-coating a chloroform solution onto glass substrates (see the Experimental Section for details). The absorption spectra were similar to those obtained from solution with absorption maxima at 338 , 400 , and $425 \mathrm{~nm}$, with the latter being slightly bathochromically shifted by about $5 \mathrm{~nm}$ for $\mathbf{Q P P}_{-}{ }^{{ }^{\mathbf{B}} \mathbf{B u}}$ and $\mathbf{Q P P}-\mathbf{P h C N}$. QPPPhCN exhibited an additional red-shifted shoulder at $440 \mathrm{~nm}$ (see Fig. S15 in the Supporting Information for spectra). It is noteworthy that the relative intensity of the peaks at $\lambda_{\mathrm{abs}}=400$ and $425 \mathrm{~nm}$ of QPP-BTh was significantly reduced compared to the other two compounds. The peaks at $\sim 400$ and $\sim 425 \mathrm{~nm}$ can be attributed to $0-1$ and $0-0$ transitions, respectively, and it has been shown that the relative intensity of these two peaks is correlated to aggregation by $\pi$ stacking. ${ }^{30}$ While for monomeric species, the $0-0$ transition should be more intense than the $0-1$ transition (as observed for all three compounds in solution), the relative intensities get reversed for $\pi$-stacked dimers due to electron-phonon coupling. ${ }^{30}$
In the thin films this reversed intensity was found for both QPP-BTh and QPP-PhCN, but not for QPP- ${ }^{\text {B }} \mathbf{B P h}$, suggesting that the first two compounds have a pronounced tendency to form $\pi$-stacked aggregates in the solid state compared to the latter. A reduced tendency of $\mathbf{Q P P}{ }^{{ }^{t} \mathbf{B u P h}}$ to form $\pi$ stacks might be explained by steric effects of the additional tertbutyl groups and is supported by single-crystal X-ray structure analysis of crystals obtained also from chloroform (see discussion below). All three thin films fluoresce when excited at $\lambda_{\mathrm{ex}}=402 \mathrm{~nm}$ (Fig. S15). The emission of the QPP- ${ }^{t} \mathbf{B u P h}$ film was much more intense compared to the other two films. All films showed similar emission behavior with a maximum in the blue range at approximately $490 \mathrm{~nm}$ and another one in the green range at approximately $535 \mathrm{~nm}$. The relative intensity of these two peaks differs for each compound. Similar to solution, the emission spectrum of QPP-BTh as a thin film exhibited a maximum at $\lambda_{\text {em }}=537$ $\mathrm{nm}$ with an additional shoulder at $\lambda_{\mathrm{em}}=494 \mathrm{~nm}$. The fluorescence of the thin films of $\mathbf{Q P P}^{\mathbf{t}}{ }^{\mathbf{B u}}$ and $\mathbf{Q P P}-\mathbf{P h C N}$ showed a completely different behavior compared to the one of the solution (see above). The thin-film-emission spectra of both compounds look quite similar, with the peak at $\lambda_{\mathrm{em}}=490 \mathrm{~nm}$ being more pronounced than the peak at $\lambda_{\mathrm{em}}=533 \mathrm{~nm}$ and at $\lambda_{\mathrm{em}}=536 \mathrm{~nm}$, respectively. Thus, in the thin films all three compounds have similar Stokes shifts between 3,107 and $3,342 \mathrm{~cm}^{-1}$. The optical properties of the films are summarized in Table 2 .

To investigate the film morphology, optical microscopic pictures were taken. The use of a polarization filter revealed that all three films were almost completely amorphous, but a few small crystallites with a size of a few micrometers could be found as well (Fig. S16). When irradiating with $\lambda_{\mathrm{ex}}=385 \mathrm{~nm}$, the film of QPP- ${ }^{\mathbf{t}} \mathbf{B u P h}$ showed a homogenous green luminescence. For QPP-BTh and QPP-PhCN, this could not be seen, most likely due to the much weaker emission intensity of these films as already pointed out above. Remarkably, in all three films the crystallites showed blue emission. 
Table 2 Optical properties of thin-films of QPP-BTh, QPP-Pht ${ }^{t} \mathrm{Bu}$, and QPP-PhCN

\begin{tabular}{|c|c|c|c|c|c|}
\hline Compd & $\lambda_{\mathrm{abs}}^{\mathrm{a}, \mathrm{b}}[\mathrm{nm}]$ & $\frac{I\left(\lambda_{0-0}\right)^{c}}{I\left(\lambda_{0-1}\right)}$ & $\begin{array}{l}\lambda_{\mathrm{em}}{ }^{\mathrm{a}}[\mathrm{nm}] \\
\left(\lambda_{\mathrm{ex}}\right)[\mathrm{nm}]\end{array}$ & $\frac{I\left(\lambda_{\mathrm{em}, 1}\right)^{\mathrm{d}}}{I\left(\lambda_{\mathrm{em}, 2}\right)}$ & Stokes shift $\tilde{\mathrm{v}}\left[\mathrm{cm}^{-1}\right]$ \\
\hline QPP-BTh & 424 & 0.85 & $\begin{array}{l}494,537 \\
(402)\end{array}$ & 0.67 & 3342 \\
\hline QPP-Pht ${ }^{t} \mathrm{Bu}$ & 426 & 1.10 & $\begin{array}{l}491,533 \\
(402)\end{array}$ & 1.10 & 3107 \\
\hline QPP-PhCN & $\begin{array}{l}424 \\
440^{\text {sh }}\end{array}$ & 0.88 & $\begin{array}{l}490,536 \\
(402)\end{array}$ & 1.28 & 3177 \\
\hline
\end{tabular}

${ }^{a}$ Measured in thin-films spin-coated from $\mathrm{CHCl}_{3}$ at rt.

bAbsorption maximum at the longest wavelength; sh, shoulder.

Intensity ratio between the $0-0$ and $0-1$ transitions.

Intensity ratio between the first and second emission peak.

It can, therefore, be concluded that the blue emission seen in the fluorescence spectra (Fig. S15) corresponds to crystalline parts, while the green emission peak is correlated with amorphous phases in the solid state.

\section{Single-Crystal X-Ray Structure Analysis}

As mentioned already in the introduction, we were interested in understanding whether the preferred tight cofacial packing of the QPP $\pi$ planes observed previously for various structures is "robust" even for QPP with additional aromatic substituents, which not only have a higher steric demand but are also able to additionally interact with the backbone or themselves, e.g., by competing $\pi$-stacking, ${ }^{9-11}$ London dispersion, ${ }^{12}$ or S-S interactions. ${ }^{37,38}$ Single crystals were either grown by slow evaporation of the solvent of a concentrated QPP solution in chloroform or by vapor diffusion into such a solution. All solvates crystallized in the triclinic space group $P$ - 1 . In all four crystal structures the prominent formation of cofacial $\pi-\pi$ dimers was found, in accordance to those previously described. ${ }^{22-24}$ However, in none of the structures the QPPs formed a continuous $\pi$-stacked pattern. Nevertheless, to compare the dimer formation by $\pi$ stacking, the degree of overlap of the $\pi$-surfaces can best be described by the offset in $x$ - and $y$-direction, where $x$ is defined as the long axis of the $\pi$ system and $y$ as the short axis (for details see Fig. S21 in the Supporting Information).

From QPP-BTh two solvates, both grown by vapor diffusion of $n$-hexane into chloroform solutions with different starting concentrations, were obtained. The first one (solvate $\alpha$ ) was grown from a concentrated solution $(c=0.37 \mathrm{mM})$. Two molecules were found in the asymmetric unit (Figure $5 \mathrm{a}$ ).

The torsion angles of the substituents are $\Theta=42-46^{\circ}$ for one QPP and $\Theta=34-36^{\circ}$ for the other QPP molecule. Solvent molecules (approximately four molecules per unit cell) were also detected, but had to be removed via the SQUEEZE $^{39,40}$ routine in PLATON due to a large degree of disorder. One-dimensional $\pi$ stacks of alternating dimers A and $B$ (Figure $5 \mathrm{~g}$ ) are formed by the blue-colored molecule of the asymmetric unit. The corresponding distances of the extended planes are $d_{\pi, \mathrm{A}}=3.53 \AA$ and $d_{\pi, \mathrm{B}}=4.27 \AA$, respectively. The latter distance cannot be considered a $\pi$-stacking motif, as it is significantly larger than the commonly defined distance for $\pi-\pi$ stacking (max. $3.8 \AA) .{ }^{11}$ The stacking of the benzothiophenyl groups $\left(d_{\mathrm{Ar}-\mathrm{Ar}, \mathrm{C}}=3.23 \AA\right.$; Figure $\left.5 \mathrm{f}\right)$ seems to be dominating in this motif. Adjacent $\pi$-stacked ribbons are separated by isolated dimers D with $d_{\pi, \mathrm{D}}=3.46 \AA$ (Figure $5 \mathrm{~b}, \mathrm{c}$ ), which are formed by two molecules belonging to the QPP highlighted in red in the asymmetric unit (Figure 5a,g).

Starting with a lower concentration $(0.12 \mathrm{mM})$, a different solvate $(\beta)$ was formed, in which only one QPP molecule and one hexane molecule, but no chloroform, are found in the asymmetric unit (Figure 6 ). Two alternating $\pi$ stacking motifs (A and B; Figure 6a,b) with $d_{\pi, \mathrm{A}}=3.78 \AA$ And $d_{\pi, \mathrm{B}}=3.38$ A form a brickwall-like arrangement (Figure 6f), but only very low molecular overlaps exist $\left(d_{\mathrm{x}, \mathrm{A}}=14.6 \AA\right.$ $d_{\mathrm{x}, \mathrm{B}}=10.9 \AA$ ).$n$-Hexane is incorporated in between two adjacent $\pi$-planes, where it is aligned in a similar way, as alkanes assemble on a graphene layer or on hexabenzoovalenes (Figure $6 \mathrm{c}$ ). ${ }^{41}$ Here, the benzothiophene units interact via weak, highly offset $\pi$ stacking with $d_{\mathrm{Ar}-\mathrm{Ar}, \mathrm{C}}=3.66 \AA$ and $d_{\mathrm{Ar}-\mathrm{Ar}, \mathrm{D}}=3.55 \AA$ (Figure $6 \mathrm{~d}, \mathrm{e}$ ).

Single crystals of $\mathbf{Q P P}-\mathbf{P h}^{\mathbf{t}} \mathbf{B u}$ were grown by vapor diffusion of $n$-hexane into a chloroform solution (Figure 7). The asymmetric unit consists of two QPP molecules and half a molecule $n$-hexane (Figure 7a). The extended planes of these molecules are oriented in an angle of approximately $90^{\circ}$ to each other. The two molecules are stacked via the void formed by the unsubstituted triptycene wings of one molecule and one phenylene substituent of the other one. The two molecules in the asymmetric unit crystallized as two conformers with regard to the torsion of the phenylene substituents. In one conformer both substituents are distorted by the same degree of $\Theta=42^{\circ}$, whereas the substituents of the other conformer have different torsion angles of $\Theta_{3}=29^{\circ}$ and $\Theta_{4}=76^{\circ}$. The comparably large 
a)

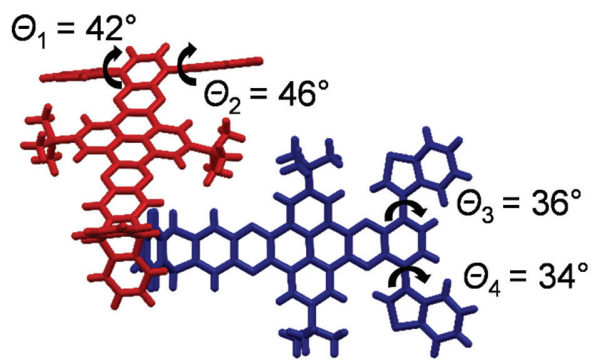

d)

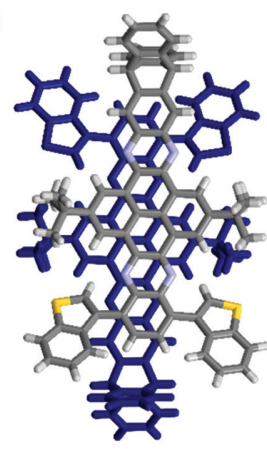

A

f)

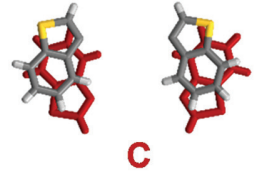

e)

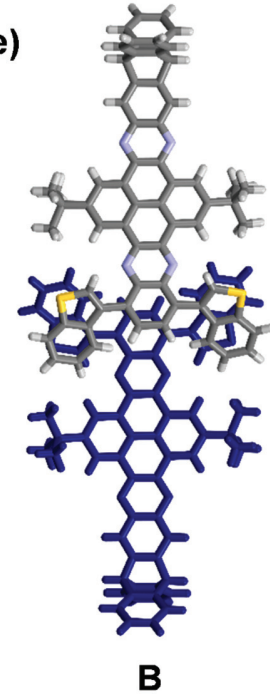

b)

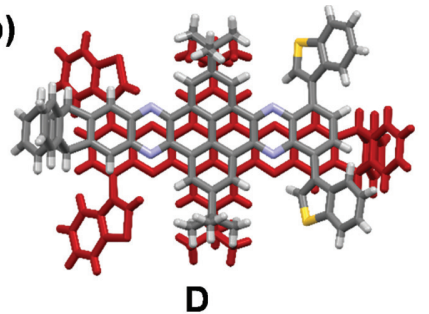

c)

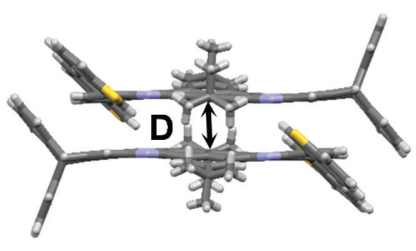

g)

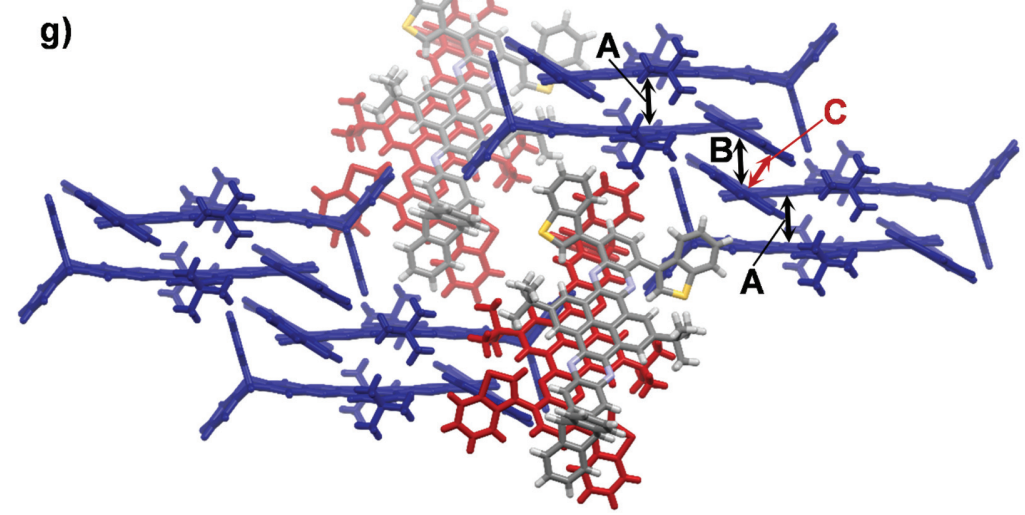

Figure 5 Single-crystal X-ray structure of QPP-Bth of solvate $\alpha$ crystallized by vapor diffusion of $n$-hexane into a $\mathrm{CHCl}_{3}$ solution ( $\left.0.37 \mathrm{mM}\right)$. (a) Asymmetric unit. (b-e) QPP $\pi$-stacking motifs. Colors of the QPP molecules are correlated with the colors in the asymmetric unit. (f) Structural overlap

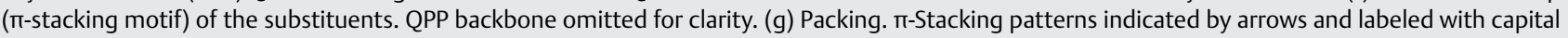
letters.

torsion of the latter can be attributed to a packing effect and can be explained by attractive dispersion interactions $\left(d_{\mathrm{CH}-\pi}=2.98-3.04 \AA\right)$ with the triptycene unit of the adjacent molecule. ${ }^{12}$ Only one conformer (highlighted in red) forms a $\pi$-stacked dimer (motif A; Figure $7 \mathrm{~b}, \mathrm{c}$ ), with offset values in $x$ - and $y$-direction of only $d_{\mathrm{x}, \mathrm{A}}=1.45 \AA$ and $d_{\mathrm{y}, \mathrm{A}}=1.11 \AA$, respectively. The distance between the planes is $d_{\pi, \mathrm{A}}=3.42 \AA$, which matches exactly the $\pi-\pi$ distance found for the chloroform solvate of unsubstituted QPP reported previously. ${ }^{24}$ The other conformer forms isolated voids via its extended plane, which is visualized using the void function in the program "Mercury" with a probe radius of $1.8 \AA$ (Figure 7d). These voids are filled with disordered $n$ hexane, which was removed by the SQUEEZE routine function. ${ }^{39,40}$ The formation of voids with this kind of compound is somehow counterintuitive, as it neither has a shape that is able to prevent close-packing nor does it have strong directional interactions that favor this packing motif. The presence of both $n$-hexane (approximately $1.5 \mathrm{~mol}$ per asymmetric unit) and additional tert-butyl groups suggests that dispersion is an important factor for stabilizing this structure. ${ }^{12}$ Short contacts of $d_{\mathrm{CH} \cdots \mathrm{HC}}=2.53 \AA$ between these tert-butyl groups of the molecule highlighted in red and the tert-butyl group of the one highlighted in blue (Figure 7d) exist. Attractive dispersion interactions have already been found previously for the tert-butyl groups of the parent $\mathrm{QPP}^{23}$ The additional tert-butyl groups of the substituents also seem to prevent $\pi$ stacking of the substituents due to their steric demand.

QPP-PhCN is structurally related to previously published QPP-CN, where the cyano groups are directly attached to the QPP backbone. ${ }^{24}$ Thus, changes in the crystal packing of QPP-PhCN can be directly related to the phenylene spacers between the cyano groups and the backbone and is therefore an ideal candidate to investigate the impact of additional aromatic groups. QPP-PhCN was crystallized by slow evaporation of a chloroform solution (Figure 8). The structure is built up by a continuous onedimensional $\pi$ stacking of alternating dimers $A$ and $B$ (Figure 8a,b) with $d_{\pi, \mathrm{A}}=3.43 \AA$ and $d_{\pi, \mathrm{B}}=3.58 \AA$ to form a brickwall-like arrangement (Figure $8 \mathrm{f}$ ) similar to the ones found for QPP-CN $\left(d_{\pi}=3.35-3.45 \AA\right) .{ }^{24}$ One of these $\pi-\pi$ 
a)

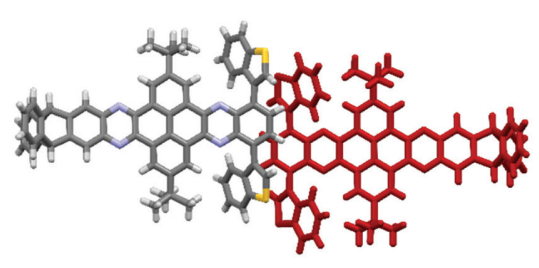

A

d)

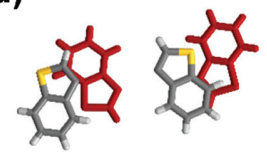

c e)

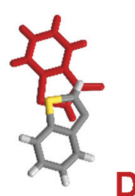

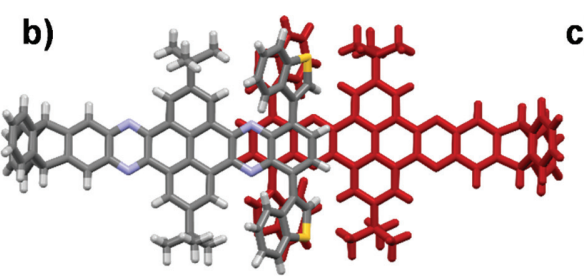

B c)

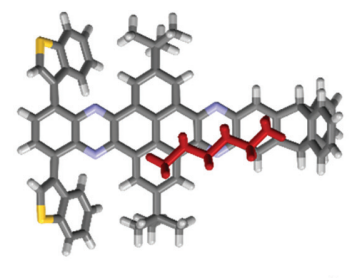
$\pi$-stacking motifs. (c) VdW interaction between $n$-hexane and the extended QPP $\pi$-plane. (d and e) Structural overlap with weak $\pi$-stacking of the substituents. QPP backbone omitted for clarity. S-S interactions in motif D. (f) Packing. $\pi$-Stacking patterns indicated by arrows and labeled with capital letters. Short contacts indicated by dotted lines.

a)

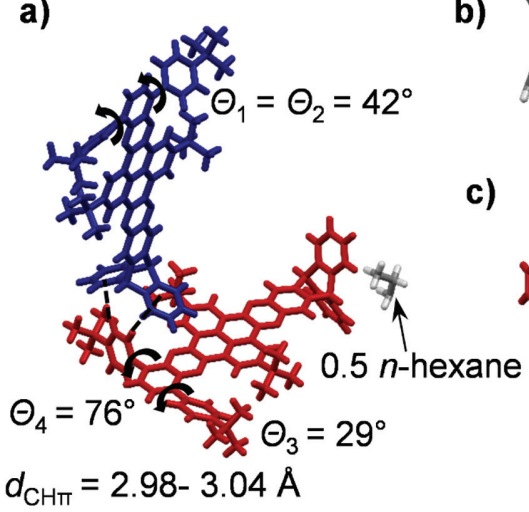

b)

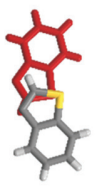

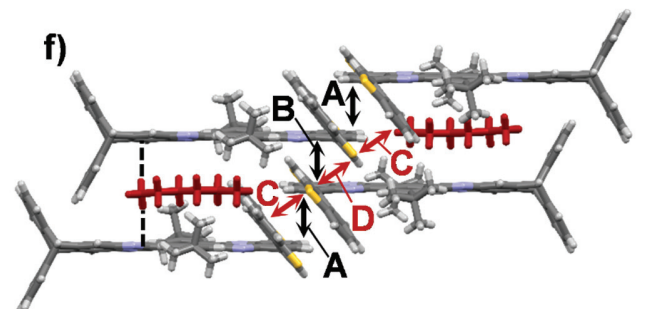

Figure 7 Crystal structure of QPP- ${ }^{{ }^{B} \text { BuPh }}$ crystallized by vapor diffusion of $n$-hexane into a $\mathrm{CHCl}_{3}$ solution: (a) asymmetric unit. (b and c) QPP $\pi$-stacking motifs. Colors of the QPP molecules are correlated with the colors in the asymmetric unit. (d) Packing. Voids shown in yellow were generated in mercury with a probe radius of $1.8 \AA$; $\pi$-stacking patterns indicated by arrows and labeled with capital letters. Short contacts indicated by dotted lines.

dimers has a high molecular overlap with offset values in $x$ and $y$-direction of only $d_{\mathrm{x}, \mathrm{A}}=1.01 \AA$ and $d_{\mathrm{y}, \mathrm{A}}=0.72 \AA$, respectively, whereas the molecules of the second dimer are displaced by a large degree in $x$-direction $\left(d_{\mathrm{x}, \mathrm{B}}=10.3 \AA\right)$. The structural overlaps are also very similar to those found in QPP-CN solvates. ${ }^{24}$ Dipolar antiparallel $\mathrm{CN}$ interactions with $\mathrm{C} \cdots \mathrm{N}$ distances of $d_{\mathrm{C}-\mathrm{N}}=3.24-3.54 \AA$ and $\mathrm{CN}^{\cdots} \mathrm{C}$ angles of $\Theta_{\mathrm{CNC}}=88-104^{\circ}$, similar to those described in the literature, ${ }^{24,42}$ build up one-dimensional ribbons (Figure 8c). Enclathration of chloroform (approximately 4.3 molecules per unit cell) was observed, but only one molecule could be resolved. Thus, $\mathrm{Cl}-\mathrm{N}$ interactions, ${ }^{43}$ which were found in the case of $\mathbf{Q P P}-\mathbf{C N}^{24}$ solvates, could not be seen in QPP-PhCN. Therefore, these interactions do not seem to play an important role in stabilizing the QPPPhCN structure as it was postulated for QPP-CN. ${ }^{24}$ Instead, a halogen bonding with the phenylene substituent occurs, ${ }^{44}$ where the chlorine atom is located over the rim of the $\mathrm{C}-\mathrm{C}$ bond of two unsubstituted carbon atoms of the phenylene unit $\left(d_{\mathrm{Cl}-\mathrm{C}}=3.53 \AA \AA\right.$; Figure $\left.8 \mathrm{~d}\right)$. Apart from that there are no pronounced differences in the structures of QPP-PhCN and QPP-CN and although they are not isomorphous, the additional phenylene units do not seem to disturb the packing significantly. Nevertheless, they may play a role in 
a)

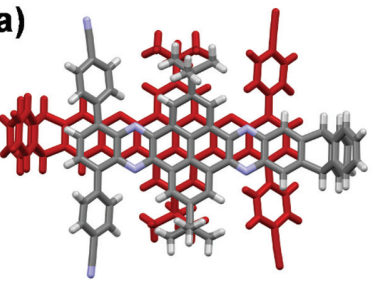

A

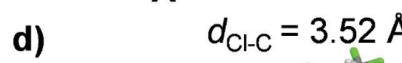

d)

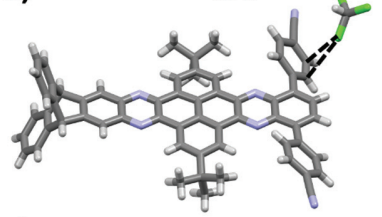

e)

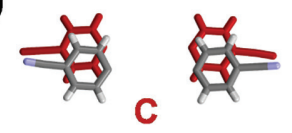

b)

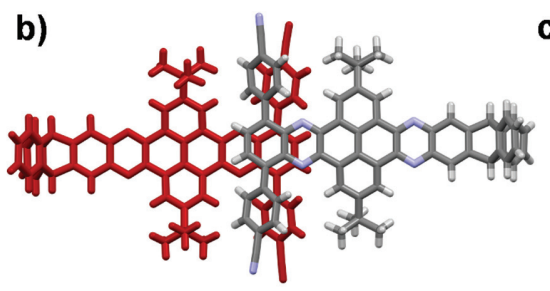

B

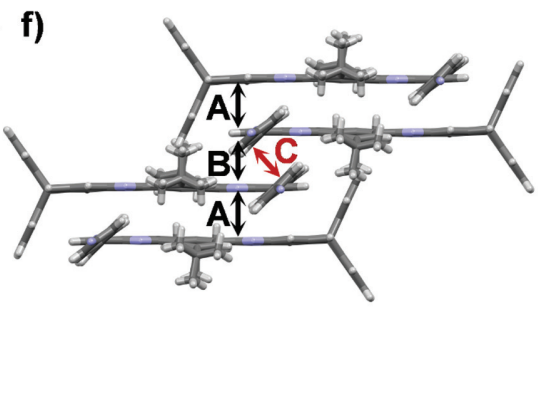

c)
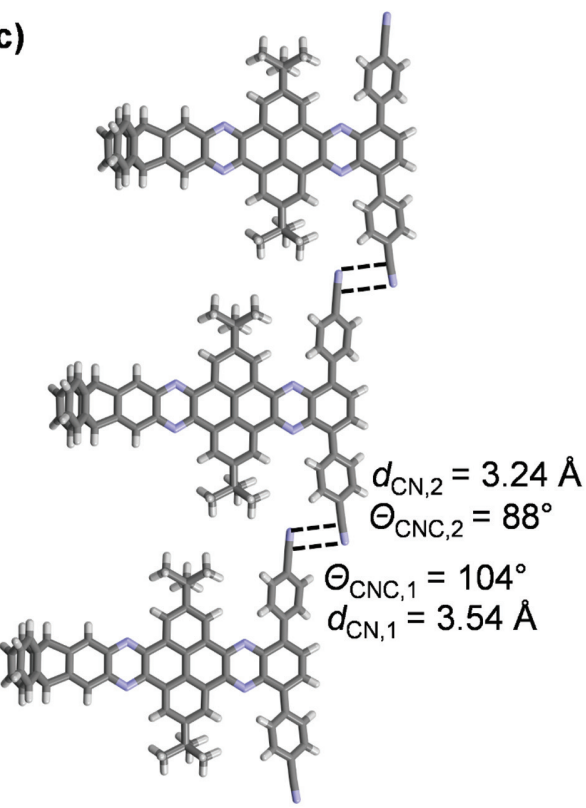

Figure 8 Single-crystal X-ray structure of QPP- ${ }^{\text {BuPh }}$ crystallized by slow evaporation of a $\mathrm{CHCl}_{3}$ solution: (a and b) QPP $\pi$-stacking motifs. (c) Onedimensional ribbons formed by dipolar $\mathrm{CN}-\mathrm{CN}$ interactions. (d) Halogen bonding between $\mathrm{CHCl}_{3}$ and phenylene ring. (e) Structural overlap with $\pi$ stacking of the substituents. QPP backbone omitted for clarity. (f) Packing; solvent molecules are omitted for clarity; $\pi$-stacking patterns indicated by arrows and labeled with capital letters. Short contacts indicated by dotted lines.

terms of charge transport, since additional $\pi$ stacking of adjacent substituents can be found here $\left(d_{\mathrm{Ar}-\mathrm{Ar}, \mathrm{C}}=\right.$ $3.34 \AA$; Figure 8e). As mentioned previously, we were interested in stacking arrangements, which favor efficient charge transport and in this solvate the molecules are arranged in a coplanar $\pi$-stacked fashion, which may allow so. While the large molecular overlap of dimer A suggests strong electron coupling; the dimer $B$, that has a much smaller molecular overlap, presents additional $\pi$ stacking of the substituents probably enhancing the coupling. Similarly,

Table 3 Crystallographic parameters, distances, and angles of all QPPs ${ }^{\mathrm{a}}$

\begin{tabular}{|c|c|c|c|c|c|c|c|c|c|c|c|c|c|}
\hline \# & Compd & $\begin{array}{l}\text { Solvent; } \\
\text { conc./ } \\
\text { (method) }^{\mathrm{b}}\end{array}$ & $\begin{array}{l}\text { Space } \\
\text { group }\end{array}$ & $N_{\text {asym }}{ }^{c}$ & $Z^{d}$ & $\begin{array}{l}\text { Enclathr. } \\
\text { Solv. }^{\mathrm{e}}\end{array}$ & $\Theta_{\text {Ar }}\left[{ }^{\circ}\right]^{f}$ & $\begin{array}{l}d_{\mathrm{Ar}-\mathrm{Ar}} \\
{[\AA \AA]^{\dagger}}\end{array}$ & $\begin{array}{l}\text { Other short } \\
\text { contacts }[\AA]^{\mathrm{a}}\end{array}$ & motif $^{9}$ & $d_{x}[\AA]^{h}$ & $d_{y}[\AA]^{h}$ & $d_{\pi-\pi}[\AA]^{i}$ \\
\hline 1 & & $\begin{array}{l}\mathrm{CHCl}_{3} ; \boldsymbol{\alpha} \\
0.37 \mathrm{mM}(\mathrm{A})\end{array}$ & $P 1$ & 2 & 4 & $2 \mathrm{~mol}^{\mathrm{sq}, *}$ & $\begin{array}{l}42-46 \\
34-36\end{array}$ & $\begin{array}{l}3.23(C) \\
3.66(C)\end{array}$ & $\begin{array}{l}- \\
- \\
-\end{array}$ & $\begin{array}{l}\text { A } \\
B \\
D\end{array}$ & $\begin{array}{l}1.61 \\
13.7 \\
0.09\end{array}$ & $\begin{array}{l}0.83 \\
0.53 \\
1.18\end{array}$ & $\begin{array}{l}3.53 \\
4.27 \\
3.46\end{array}$ \\
\hline 2 & QPP-BTh & $\begin{array}{l}\mathrm{CHCl}_{3} ; \\
\boldsymbol{\beta} 0.12 \mathrm{mM}(\mathrm{A})\end{array}$ & $P 1$ & 1 & 2 & $1 n$-Hex & $48-49$ & 3.55 (D) & $\begin{array}{l}3.76(\mathrm{~S}-\mathrm{S}) \\
2.62(\mathrm{CH}-\pi) \\
2.90(\mathrm{CH}-\pi)\end{array}$ & $\begin{array}{l}A \\
B\end{array}$ & $\begin{array}{l}14.7 \\
10.9\end{array}$ & $\begin{array}{l}2.01 \\
0.39\end{array}$ & $\begin{array}{l}3.78 \\
3.38\end{array}$ \\
\hline 3 & QPP-Ph ${ }^{t} \mathrm{Bu}$ & $\begin{array}{l}\mathrm{CHCl}_{3} ; \\
1.11 \mathrm{mM}(\mathrm{A})\end{array}$ & $P 1$ & 2 & 4 & $\begin{array}{l}0.5+0.5^{\text {sq }} \\
n-H e x\end{array}$ & $\begin{array}{l}42 \\
29 ; 76\end{array}$ & & $\begin{array}{l}2.98(\mathrm{CH}-\pi) \\
3.04(\mathrm{CH}-\pi)\end{array}$ & A & 1.45 & 1.11 & 3.42 \\
\hline 4 & QPP-PhCN & $\mathrm{CHCl}_{3}(\mathrm{~B})$ & $P 1$ & 1 & 2 & $\begin{array}{l}1+1.6^{\mathrm{sq}} \\
\mathrm{CHCl}_{3}\end{array}$ & $36-44$ & $3.34(C)$ & $\begin{array}{l}3.24-3.54(\mathrm{C}-\mathrm{N}) \\
3.53(\mathrm{Cl}-\pi)\end{array}$ & $\begin{array}{l}A \\
B\end{array}$ & $\begin{array}{l}1.01 \\
10.3\end{array}$ & $\begin{array}{l}0.72 \\
0.20\end{array}$ & $\begin{array}{l}3.43 \\
3.58\end{array}$ \\
\hline
\end{tabular}

a Values have been determined for two adjacent molecules. For the determination procedure, see the Supporting Information.

${ }^{\mathrm{b}} \mathrm{A}$ : gas diffusion of $n$-hexane at rt; B: slow evaporation of solvent.

'Number of molecules in the asymmetric unit; refined solvate molecules not counted.

${ }^{\mathrm{d}}$ Total number of molecules in the unit cell including refined solvate molecules

e Number of enclathrated molecules in the asymmetric unit; sq: squeezed due to disorder; number estimated from electron density; *largely disordered; no differentiation between $\mathrm{CHCl}_{3}$ or $n$-hexane possible.

${ }^{\mathrm{f}}$ Torsion angels and $\pi$ contacts (given as the shortest C-C distance) of the substituents.

The letters indicate the $\pi$ stacking motifs as shown in Figures 5-8. Displacements and $\pi$ distances are given in the next three columns.

hDisplacement of $\pi$-planes along the $x$ - and $y$-axes; determination procedure and corresponding coordinate system is described in Section 7.2 in the Supporting Information.

'The $\pi$-ா-stacking distance of the QPP backbones; $\pi$-planes were calculated from 14 atoms in the center of the six linearly annulated rings (see the Supporting Information for details). 
the stacking of benzothiophene substituents found in both solvates of QPP-BTh might also contribute to the coupling of adjacent QPPs. Table 3 summarizes the crystallographic details described above.

\section{Conclusion}

In conclusion, three triptycene-endcapped QPP derivatives bearing aromatic substituents have been synthesized and investigated in solution and in the solid state as thin films. The absorption spectra of these films indicated increased $\pi$ stacking tendency of QPP-BTh and QPP-PhCN compared to QPP- ${ }^{\mathbf{B}} \mathbf{B u P h}$. In the emission spectra two peaks were found, which were associated with a crystalline and an amorphous phase, respectively.

By single-crystal X-ray diffraction, $\pi$-dimer formation could be observed in all four structures to a different degree, showing that the directing capability of the triptycene endcapping is also pronounced in the presence of larger aromatic substituents that could disturb the packing by competing $\pi$ stacking interactions, which would especially be expected for the benzothiophene-substituted QPP-Bth. However, a preferred brickwall-type arrangement, which potentially allows efficient charge transport, was maintained only in the case of QPP-PhCN, probably due to the strong directing effect of the cyano groups, and in one of the two solvates of QPP-Bth, but only with a poor structural overlap. The observation of $\pi$ dimers in all crystal structures underscores the robust directing effect of triptycene end-capping, making it an attractive synthon for crystal engineering purposes. Currently, we are further investigating the scope of this unusual but unique crystal engineering synthon to construct more complex structures in the solid state.

\section{Experimental Section}

\section{General Remarks}

All reagents and solvents were purchased from Fisher Scientific, Alfa Aesar, Sigma-Aldrich, or VWR and were used without further purification unless otherwise noted. For thin-layer chromatography, silica gel 60 F254 plates from Merck were used and examined under UV irradiation $(\lambda=254$ and $365 \mathrm{~nm}$ ). Flash column chromatography was performed on silica gel from Sigma-Aldrich (particle size 0.04-0.063 $\mathrm{mm}$ ) with petroleum ether and dichloromethane as the eluents. Melting points (not corrected) were measured by using a Büchi Melting Point B-545 instrument. IR spectra were recorded on a Ge ATR crystal by using a Bruker Lumos spectrometer. NMR spectra were recorded by using Bruker Avance DRX (300 MHz), Bruker Avance III (300 MHz), Bruker Avance III (400 MHz), and
Bruker Avance III (500 MHz) spectrometers. Chemical shifts $(\delta)$ are reported in parts per million ( $\mathrm{ppm}$ ) relative to trace $\mathrm{CHCl}_{3}$ in the corresponding deuterated solvent. HRMS experiments were carried out by using a Fouriertransform ion cyclotron resonance (FT-ICR) mass spectrometer solariX (Bruker Daltonik, Bremen, Germany) equipped with a 7.0 $\mathrm{T}$ superconducting magnet and interfaced to an Apollo II Dual ESI/MALDI source with DCTB (trans-2-[3-(4-tert-butylphenyl)-2-methyl-2-propenylidene]malononitrile) as the matrix. Absorption spectra were recorded on a Jasco UV-VIS V-730. Emission spectra were recorded on a Jasco FP-8300. Quantum yields were determined using an emission spectrometer equipped with an integration sphere (LabSphere; diameter 6", coated with Spectraflect). The system was calibrated with a primary light source. ${ }^{45}$ The procedure from Würth et $\mathrm{al}^{46}$ was used with following settings for the emission spectrometer: bandwidth $3 \mathrm{~nm}$, emission bandwidth $3 \mathrm{~nm}$, and integration time $1 \mathrm{~s}$. For thin-film preparation, glass substrates were cleaned in an iso-propanol bath under ultrasound for $2 \mathrm{~min}$, and then in an acetone bath for $2 \mathrm{~min}$. Spin-coating was carried out with a chloroform solution $(1-3 \mathrm{mg} / \mathrm{mL}$; filtrated with $0.45 \mu \mathrm{m}$ microfilter) using a spin coater (Model: Spin 150) of S.P.S. The velocity was set up at $500 \mathrm{rpm}$ for $30 \mathrm{~s}$. For optical spectroscopy, a noncoated glass substrate was used as a reference. Emission spectra of films were recorded with $\lambda_{\mathrm{ex}}=402 \mathrm{~nm}$. Microscopic images were recorded using a Zeiss Imager.Z2m microscope. The images were taken in the transmission mode with enlarging factors of $10 \times, 25 \times$, and $50 \times$, respectively. Optionally an optical polarization filter was used. For fluorescence microscopic images the thin films were excited with $\lambda_{\mathrm{ex}}=385 \mathrm{~nm}$ in the reflection mode. Electrochemical data were obtained in a solution of TBAPF (tetra- $n$-butyl ammonium hexafluorophosphate) (0.1 M) in 0 -DCB that contained $1 \mathrm{mM}$ of the investigated compound, as indicated. Ferrocene $(1 \mathrm{mM})$ was used as an internal standard. Cyclic voltamograms were obtained at a scan rate of $0.05 \mathrm{~V} \mathrm{~s}^{-1}$ with a Pt working electrode $\left(0.78 \mathrm{~mm}^{2}\right)$, a Pt counter electrode, and an $\mathrm{Ag}$ reference electrode. Crystal data and details of the structure determinations are compiled in Tables S2-S9 in the Supporting Information. Crystal structure analysis was accomplished by using a STOE Stadivari diffractometer with a copper source $\left[\lambda\left(\mathrm{Cu}_{\mathrm{K \alpha}}\right)=1.54178 \AA\right.$ A $]$. Data were corrected for sample illumination, air and detector absorption, Lorentz, and polarization effects ${ }^{47}$; absorption by the crystal was treated numerically (Gaussian grid). ${ }^{47,48}$ The structures were solved by using intrinsic phasing ${ }^{49}$ or direct methods with dual-space recycling ${ }^{50}$ and refined by using full-matrix least-squares methods on F2 against all unique reflections. ${ }^{51}$ All non-hydrogen atoms were given anisotropic displacement parameters. Hydrogen atoms were input at calculated positions and refined with a 
riding model. When necessary, disordered groups and/or solvent molecules were subjected to suitable geometry and adp restraints and/or constraints. CCDC1922357-1922360 contains the supplementary crystallographic data for this article. These data are provided free of charge by the Cambridge Crystallographic Data Centre (https://www. ccdc.cam.ac.uk/).

\section{Synthesis}

2,11-Di-tert-butyl-5,8-bis(benzo[b]thiophen-3-yl)15,20-dihydro-15,20-[1,2]benzenonaphtho[2,3-i] quinoxalino $\left[2^{\prime}, 3^{\prime}: 9,10\right]$-phenanthro[4,5-abc] phenazine (QPP-BTh)

Under an argon atmosphere, water $(0.24 \mathrm{~mL})$, toluene $(0.45 \mathrm{~mL})$, and 1,4-dioxane $(1.3 \mathrm{~mL})$ were added to QPP$\mathbf{B r}^{24}$ (50 mg, $58.6 \mu \mathrm{mol}$ ) and benzo[b]thiophen-3-ylboronic acid $(23 \mathrm{mg}, 129 \mu \mathrm{mol})$. After degassing for $10 \mathrm{~min}$, $\mathrm{Pd}_{2}(\mathrm{dba})_{3}(1.6 \mathrm{mg}, 1.8 \mu \mathrm{mol})$ and $\mathrm{P}(\text { o-tol })_{3}(4.5 \mathrm{mg}, 14.7$ $\mu \mathrm{mol})$ were added and the reaction mixture was stirred vigorously at $60{ }^{\circ} \mathrm{C}$ for $17 \mathrm{~h}$. After cooling to room temperature, the mixture was diluted with DCM $(40 \mathrm{~mL})$, the layers were separated, and the organic phase was subsequently dried over $\mathrm{Na}_{2} \mathrm{SO}_{4}$. After removal of the solvent, the crude product was purified by flash column chromatography $\left(\mathrm{SiO}_{2}\right.$, light petroleum ether/ethyl acetate, $30: 1)$. The fraction containing the product was further purified by recycling HPLC (DCM) to give QPP-BTh as a yellow solid (8 mg, $8.34 \mu \mathrm{mol}, 14 \%)$. m.p.: $356{ }^{\circ} \mathrm{C}$ (decomp.). ${ }^{1} \mathrm{H}-\mathrm{NMR}$ $\left(\mathrm{CDCl}_{3}, 600 \mathrm{MHz}\right): \delta[\mathrm{ppm}]=9.64\left(\mathrm{~d},{ }^{3} \mathrm{~J}=2.0 \mathrm{~Hz}, 2 \mathrm{H}, \mathrm{H}-1\right)$, 9.15 (d, ${ }^{3} \mathrm{~J}=2.0 \mathrm{~Hz}, 2 \mathrm{H}, \mathrm{H}-3$ ), 8.32 (s, 2H, H-14), 8.21 (s, $2 \mathrm{H}$, $H-5 b), 8.08$ (d, $\left.{ }^{3} J=8.2 \mathrm{~Hz}, 2 \mathrm{H}, H-5 \mathrm{~d}\right), 8.01$ (s, 2H, H-6), 7.91 (d, ${ }^{3} \mathrm{~J}=8.0 \mathrm{~Hz}, 2 \mathrm{H}, \mathrm{H}-5 \mathrm{~g}$ ), 7.51 (dd, ${ }^{3} \mathrm{~J}=5.3,3.3 \mathrm{~Hz}, 4 \mathrm{H}$, $H-16), 7.46\left(\mathrm{t},{ }^{3} \mathrm{~J}=7.5 \mathrm{~Hz}, 2 \mathrm{H}, \mathrm{H}-5 \mathrm{f}\right), 7.37\left(\mathrm{t},{ }^{3} \mathrm{~J}=7.5 \mathrm{~Hz}, 2 \mathrm{H}\right.$, $H-5 \mathrm{e}), 7.10\left(\mathrm{dd}^{3} \mathrm{~J}=5.6,3.0 \mathrm{~Hz}, 4 \mathrm{H}, \mathrm{H}-17\right), 5.73(\mathrm{~s}, 2 \mathrm{H}, \mathrm{H}-15)$, 1.45 (s, 18H, H-2b). ${ }^{13} \mathrm{C}-\mathrm{NMR}\left(\mathrm{CDCl}_{3}, 100 \mathrm{MHz}\right): \delta$ [ppm] $=150.9(C-3 \mathrm{~b} / 12 \mathrm{~b} / 27), 146.4(C-13 \mathrm{a} / 14 \mathrm{a}), 143.9(C-15 \mathrm{a})$, 142.4 (C-3a/12a), 142.3 (C-3a/12a), 141.4(C-13a/14a), 140.7 (C-5h), 140.3 (C-4a/5), 139.7 (C-5c), 135.2 (C-5a), 134.7 (C-3b/12b/27), 130.4 (C-5b), $129.6(C-3 b / 12 b / 27), 129.3$ (C-4a/5), 127.3 (C-6), 126.2 (C-17), $125.7(C-2), 124.7$ (C-1/3), 124.6 (C-3/1), 124.5 (C-5e), 124.4 (C-5f), 124.3 (C-5g), 124.2 (C-16), 123.0 (C-14), 122.9 (C-5d), 53.91 (C-15), 35.7 (C-2a), 31.6 ( $C-2 b)$. HRMS (MALDI): $m / z=$ 958.3166 [M] $]^{+}$(calc.: $\left.m / z=958.3164\right), 959.3237[\mathrm{M}+\mathrm{H}]^{+}$ (calc.: $m / z=959.3237)$. UV/vis $\left(\mathrm{CHCl}_{3}\right): \lambda_{\mathrm{abs}}[\mathrm{nm}]=421$, $399,336,365,277$. UV/vis (thin film): $\lambda_{\mathrm{abs}}[\mathrm{nm}]=424,402$, 338. Fluorescence $\left(\mathrm{CHCl}_{3}\right): \lambda_{\mathrm{em}}[\mathrm{nm}]\left(\lambda_{\mathrm{exc}}[\mathrm{nm}]\right)=536(401)$. Fluorescence (thin film): $\lambda_{\text {em }}[\mathrm{nm}]\left(\lambda_{\text {exc }}[\mathrm{nm}]\right)=494$ (shoulder, 402), 537 (402). PLQY $\left(\mathrm{CHCl}_{3}\right)$ : $\Phi[\%]\left(\lambda_{\text {exc }}\right.$ $[\mathrm{nm}])=33$ (420). IR (ATR): $\left[\mathrm{cm}^{-1}\right]=3067(\mathrm{w}), 2957(\mathrm{~m})$, 2924 (m), 2866 (m), 1609 (w), 1458 (m), 1421 (m), 1394 (w), $1364(\mathrm{~m}), 1325$ (m), $1300(\mathrm{w}), 1288(\mathrm{w}), 1271(\mathrm{w}), 1259(\mathrm{w})$, $1223(\mathrm{w}), 1202(\mathrm{w}), 1180(\mathrm{w}), 1153(\mathrm{~m}), 1142(\mathrm{~m}), 1119(\mathrm{w})$, 1103 (w), $1086(\mathrm{w}), 1074(\mathrm{w}), 1051(\mathrm{w}), 1022(\mathrm{w}), 935(\mathrm{w})$, $897(\mathrm{~m}), 862(\mathrm{~m}), 835(\mathrm{w}), 824(\mathrm{w}), 797(\mathrm{~m}), 785(\mathrm{w}), 758(\mathrm{~s})$, 731 (vs), 665 (w), 646 (w), $629(\mathrm{~m}), 608(\mathrm{~m})$.

\section{2,11-Di-tert-butyl-5,8-bis(4-(tert-butyl)phenyl)- 15,20-dihydro-15,20-[1,2] benzenonaphtho[2,3-i] quinoxalino[ $\left.2^{\prime}, 3^{\prime}: 9,10\right]$-phenanthro[4,5-abc]- phenazine (QPP- $\left.{ }^{t} \mathrm{BuPh}\right)$.}

A solution of diamine 1a $(44.7 \mathrm{mg}, 0.12 \mathrm{mmol})$ and diketone $2^{23}$ ( $50.0 \mathrm{mg}, 0.08 \mathrm{mmol}$ ) in chloroform $(4.4 \mathrm{~mL}$ ) and glacial acetic acid $(0.24 \mathrm{~mL})$ was stirred at $70{ }^{\circ} \mathrm{C}$ under an argon atmosphere for $17 \mathrm{~h}$. After cooling to room temperature, the solution was poured in methanol $(15 \mathrm{~mL})$ and the formed precipitate collected by vacuum filtration. The crude product was recrystallized from ethanol/chloroform to

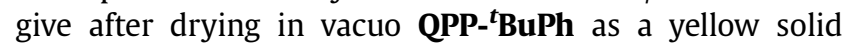
(75.9 mg, 96\%). m.p.: $>410{ }^{\circ} \mathrm{C} .{ }^{1} \mathrm{H}-\mathrm{NMR}\left(600 \mathrm{MHz}, \mathrm{CDCl}_{3}\right)$ : $\delta[\mathrm{ppm}]=9.70(\mathrm{~d}, J=2.0 \mathrm{~Hz}, 2 \mathrm{H}, H-1), 9.59(\mathrm{~d}, J=2.0 \mathrm{~Hz}$, 2H, H-3), 8.36 (s, 2H, H-14), 8.09 (s, 2H, H-6), 8.07 (d, $J=8.1 \mathrm{~Hz}, 4 \mathrm{H}, H-5 \mathrm{~b}), 7.69(\mathrm{~d}, J=8.1 \mathrm{~Hz}, 4 \mathrm{H}, H-5 \mathrm{c}), 7.52(\mathrm{dd}$, $J=5.3,3.2 \mathrm{~Hz}, 4 \mathrm{H}, H-16), 7.11(\mathrm{dd}, J=5.6,3.0 \mathrm{~Hz}, 4 \mathrm{H}, H-17)$, 5.75 (s, 2H, H-15), 1.67 (s, 18H, H-2b), 1.50 (s, 18H, H-5f). ${ }^{13}$ C-NMR $\left(\mathrm{CDCl}_{3}, 151 \mathrm{MHz}\right): \delta[\mathrm{ppm}]=150.7(\mathrm{C}-5 \mathrm{a} / 5 \mathrm{~d}), 146.5$ (C-13a/14a), 144.0 (C-15a), 142.4 (C-12a), 141.9 (C-3a), 141.4 (C-13a/14a), 140.3 (C-4a), 139.6 (C-5a/5d), 135.7 (C-5), 131.4 (C-5b), $129.6(C-6), 129.4(C-3 \mathrm{~b} / 12 \mathrm{~b} / 27), 126.2$ (C-17), 125.8 (C-2), 124.9 (C-5c), $124.7(C-1 / 3), 124.5$ $(C-3 / 1), 124.2(C-16), 123.0(C-14), 53.9(C-15), 35.9(C-2 \mathrm{a})$, 34.9 (C-5e), 31.8 (C-2b), 31.6 ( $C$-5f). HRMS (MALDI): $m / z=$ $958.4985[\mathrm{M}]^{+}$(calc.: $\left.m / z=958.4974\right), 959.5052[\mathrm{M}+\mathrm{H}]^{+}$ (calc.: $m / z=959.5057)$. UV/vis $\left(\mathrm{CHCl}_{3}\right): \lambda_{\mathrm{abs}}[\mathrm{nm}]=422$, 399, 336, 278. UV/vis (thin-film): $\lambda_{\text {abs }}[\mathrm{nm}]=426,402,339$. Fluorescence $\left(\mathrm{CHCl}_{3}\right): \lambda_{\text {em }}[\mathrm{nm}]\left(\lambda_{\text {exc }}[\mathrm{nm}]\right)=512(402)$. Fluorescence (thin film): $\lambda_{\mathrm{em}}[\mathrm{nm}]\left(\lambda_{\mathrm{exc}}[\mathrm{nm}]\right)=491(402)$, 533 (402). PLQY $\left(\mathrm{CHCl}_{3}\right): \Phi[\%]\left(\lambda_{\text {exc }}[\mathrm{nm}]\right)=30$ (372). IR (ATR): $\left[\mathrm{cm}^{-1}\right]=2959(\mathrm{w}), 2903(\mathrm{w}), 2866(\mathrm{w}), 1609(\mathrm{w})$, 1477 (w), 1460 (m), 1443 (w), 1364 (w), $1325(\mathrm{w}), 1279(\mathrm{w})$, 1244 (w), 1217 (w), $1202(\mathrm{w}), 1155(\mathrm{w}), 1117(\mathrm{w}), 1024(\mathrm{w})$, $1015(w), 945(w), 924(w), 901(w), 883(w), 860(w)$.

\section{2,11-Di-tert-butyl-5,8-bis(4-cyanophenyl)-15,20- dihydro-15,20-[1,2]benzenonaphtho[2,3-i] quinoxalino $\left[2^{\prime}, 3^{\prime}: 9,10\right]$-phenanthro[4,5-abc]- phenazine (QPP-PhCN)}

A solution of diamine $\mathbf{1 b}(14.0 \mathrm{mg}, 36.5 \mu \mathrm{mol})$ and diketone $\mathbf{2}^{23}$ (15.2 mg, $24.4 \mu \mathrm{mol}$ ) in chloroform ( $1.4 \mathrm{~mL}$ ) and glacial acetic acid $(0.07 \mathrm{~mL})$ was stirred at $70{ }^{\circ} \mathrm{C}$ under an 
argon atmosphere for $17 \mathrm{~h}$. After cooling to room temperature, the solution was poured in methanol $(4.5 \mathrm{~mL})$ and the formed precipitate collected by vacuum filtration. The product was recrystallized from ethanol/chloroform and dried in vacuum to give QPP-PhCN as an orange solid ( $8.1 \mathrm{mg}$, 37\%). m.p.: $358{ }^{\circ} \mathrm{C}$ (decomp.). ${ }^{1} \mathrm{H}-\mathrm{NMR}\left(600 \mathrm{MHz}, \mathrm{CDCl}_{3}\right): \delta$ $[\mathrm{ppm}]=9.74\left(\mathrm{~d},{ }^{3} \mathrm{~J}=2.1 \mathrm{~Hz}, 2 \mathrm{H}, \mathrm{H}-1\right), 9.44\left(\mathrm{~d},{ }^{3} \mathrm{~J}=2.1 \mathrm{~Hz}\right.$, 2H, H-3), 8.35 (s, 2H, H-14), 8.22 (d, ${ }^{3} J=8.3 \mathrm{~Hz}, 4 \mathrm{H}, H-5 \mathrm{c}$ ), 8.08 (s, 2H, H-6), 7.95 (d, ${ }^{3} \mathrm{~J}=8.3 \mathrm{~Hz}, 4 \mathrm{H}, H-5 \mathrm{~b}$ ), 7.53 (dd, $\left.{ }^{3} J=5.4,3.2 \mathrm{~Hz}, 4 \mathrm{H}, H-16\right), 7.11\left(\mathrm{dd},{ }^{3} \mathrm{~J}=5.6,3.0 \mathrm{~Hz}, 4 \mathrm{H}\right.$, $\mathrm{H}-17$ ), 5.75 (s, 2H, H-15), 1.66 (s, 18H, H-2b). ${ }^{13} \mathrm{C}-\mathrm{NMR}$ $\left(\mathrm{CDCl}_{3}, 151 \mathrm{MHz}\right): \delta[\mathrm{ppm}]=151.1(\mathrm{C}-3 \mathrm{~b} / 12 \mathrm{~b} / 27), 146.7$ (C-13a/14a), 143.9 (C-15a), 143.1 (C-5), 142.8 (C-3a), 142.1 (C-12a), 141.5(C-13a/14a), $139.7(C-4 a), 139.2(C-5 d), 132.2$ (C-5c), $131.8(C-5 b), 129.9(C-3 b / 12 b / 27), 129.8(C-6), 128.9$ (C-3b/12b/27), $126.2(C-17), 125.9(C-2), 125.2(C-1), 124.4$ (C-3), $124.2(C-16), 123.0(C-14), 119.3(C-5 a) 111.7(C-5 e)$, 53.9 ( $C-15)$, 35.9 ( $C-2 \mathrm{a}), 31.8$ ( $C-2 \mathrm{~b})$. HRMS (MALDI): $\mathrm{m} / \mathrm{z}=$ 896.3615 [M] $]^{+}$(calc.: $\left.m / z=896.3627\right), 897.3698[\mathrm{M}+\mathrm{H}]^{+}$ (calc.: $m / z=897.3700$ ), $914.3685\left[\mathrm{M}+\mathrm{H}_{2} \mathrm{O}\right]^{+}$(calc.: $m /$ $z=914.3733)$. UV/vis $\left(\mathrm{CHCl}_{3}\right): \lambda_{\text {abs }}[\mathrm{nm}]=417,396,338$, $322,299,278$. UV/vis (thin film): $\lambda_{\text {abs }}[\mathrm{nm}]=440$ (sh), 424, 402 , 341. Fluorescence $\left(\mathrm{CHCl}_{3}\right): \lambda_{\mathrm{em}}[\mathrm{nm}]\left(\lambda_{\text {exc }}[\mathrm{nm}]\right)=464$ (387). Fluorescence (thin film): $\lambda_{\text {em }}[\mathrm{nm}]\left(\lambda_{\text {exc }}[\mathrm{nm}]\right)=490$ (402), 536 (402). PLQY $\left(\mathrm{CHCl}_{3}\right): \Phi[\%]\left(\lambda_{\text {exc }}[\mathrm{nm}]\right)=22(357)$. IR (ATR): $\left[\mathrm{cm}^{-1}\right]=3360(\mathrm{w}), 2957(\mathrm{w}), 2922(\mathrm{~s}), 2853(\mathrm{w})$, 2230 (w), 1663 (w), 1634 (w), 1607 (w), 1460 (s), 1420 (w), 1396 (w), 1377 (w), $1366(\mathrm{~m}), 1325(\mathrm{~m}), 1279(\mathrm{~m}), 1261$ (s), 1225 (w), 1203 (w), 1182 (m), 1155 (m), $1146(\mathrm{~m}), 1088(\mathrm{~s})$, $1020(\mathrm{~s}), 974(\mathrm{w}), 945(\mathrm{w}), 922(\mathrm{w}), 903(\mathrm{w}), 887(\mathrm{w}), 866(\mathrm{w})$, 822 (s), 799 (vs), $770(\mathrm{w}), 743(\mathrm{~s}), 706(\mathrm{w}), 673(\mathrm{w}), 663(\mathrm{w})$, $644(\mathrm{w}), 629(\mathrm{~m}), 609(\mathrm{w})$.

\section{Funding Information}

Collaborative research center SFB1249 on N-heteropolycycles as functional materials funded by "Deutsche Forschungsgemeinschaft".

\section{Supporting Information}

Supporting information for this article is available online at https://doi.org/10.1055/s-0039-1700847.

\section{References}

(1) Gavezzotti, A. Acc. Chem. Res. 1994, 27, 309-314.

(2) Nyman, J.; Reutzel-Edens, S. M. Faraday Discuss. 2018, 211, 459-476.

(3) Price, S. L.; Price, L. S. Toward Computational Polymorph Prediction. In: Polymorphism in the Pharmaceutical Industry: Solid Form and Drug Development. Hilfiker, R.; von Raumer, M., eds; Viley-VCH: Weinheim, 2018.
(4) Day, G. M. Advances in Crystal Structure Prediction and Applications to Pharmaceutical Materials. In: Computational Pharmaceutical Solid State Chemistry. Abramov, Y. A., ed.; VileyVCH: Weinheim, 2016.

(5) (a) Beran, G. J. O. Angew. Chem. Int. Ed. 2015, 54, 396-398. (b) Beran, G. J. O. Angew. Chem. 2015, 127, 406-408.

(6) (a) Steiner, T. Angew. Chem. Int. Ed. 2002, 41, 48-76. (b) Steiner, T. Angew. Chem. 2002, 114, 50-80.

(7) Cavallo, G.; Metrangolo, P.; Milani, R., et al. Chem. Rev. 2016, 116 (04):2478-2601.

(8) Desiraju, G. R.; Parthasarathy, R. J. Am. Chem. Soc. 1989, 111, 8725-8726.

(9) Hunter, C. A.; Sanders, J. K. M. J. Am. Chem. Soc. 1990, 112, 5525-5534.

(10) Martinez, C. R.; Iverson, B. L. Chem. Sci. (Camb) 2012, 3, 2191-2201.

(11) Janiak, C. J. Chem. Soc., Dalton Trans. 2000, 3885-3896.

(12) (a) Wagner, J. P.; Schreiner, P. R. Angew. Chem. Int. Ed. 2015, 54, 12274-12296. (b) Wagner, J. P.; Schreiner, P. R. Angew. Chem. 2015, 127, 12446-12471.

(13) Brédas, J. L.; Calbert, J. P.; da Silva Filho, D. A.; Cornil, J. Proc. Natl. Acad. Sci. U. S. A. 2002, 99, 5804-5809.

(14) Reese, C.; Bao, Z. J. Mater. Chem. 2006, 16, 329-333.

(15) Abbott, L. J.; McDermott, A. G.; Del Regno, A., et al. J. Phys. Chem. B. 2013, 117, 355-364.

(16) Abbott, L. J.; McKeown, N. B.; Colina, C. M. J. Mater. Chem. A. Mater. Energy Sustain. 2013, 1, 11950-11960.

(17) Del Regno, A.; Siperstein, F. R.; Taylor, R. GD.; McKeown, N. B. Microporous Mesoporous Mater. 2013, 179, 265.

(18) Kohl, B.; Rominger, F.; Mastalerz, M. Org. Lett. 2014, 16, 704-707.

(19) Kohl, B.; Rominger, F.; Mastalerz, M. Chem. Eur. J. 2015, 21, 17308-17313.

(20) Reinhard, D.; Rominger, F.; Mastalerz, M. J. Org. Chem. 2015, 80 9342-9348.

(21) Reinhard, D.; Zhang, W-S.; Rominger, F., et al. Chem. Eur. J. 2018, 24, 11433-11437.

(22) Prantl, E.; Kohl, B.; Ryvlin, D.; Biegger, P.; Wadepohl, H.; Rominger, F.; Bunz, U. H. F.; Mastalerz, M.; Waldvogel, S. R. ChemPlusChem 2019, 84, 1239-1244.

(23) Kohl, B.; Bohnwagner, M. V.; Rominger, F.; Wadepohl, H.; Dreuw, A.; Mastalerz, M. Chem. Eur. J. 2016, 22, 646-655.

(24) Ueberricke, L.; Holub, D.; Kranz, J.; Rominger, F.; Elstner, M.; Mastalerz, M. Chem. Eur. J. 2019, 25, 11121-11134.

(25) Schleper, A. L.; Voll, C.-C. A.; Engelhart, J. U.; Swager, T. M. Synlett 2017, 28, 2783-2789.

(26) Littke, A. F.; Dai, C.; Fu, G. C. J. Am. Chem. Soc. 2000, 122, 4020-4028.

(27) Heiskanen, J. P.; Vivo, P.; Saari, N. M., et al. J. Org. Chem. 2016, 81, 1535-1546.

(28) Neto, B. A. D.; Lopes, A. S.; Wüst, M.; Costa, V. EU.; Ebeling, G.; Dupont, J. Tetrahedron Lett. 2005, 46, 6843-6846.

(29) Mancilha, F. S.; DaSilveira Neto, B. A.; Lopes, A. S., et al. Eur.J. Org. Chem. 2006, 2006, 4924-4933.

(30) Li, A. D. Q.; Wang, W.; Wang, L.-Q. Chem. Eur. J. 2003, 9, 4594-4601.

(31) Kulisic, N.; More, S.; Mateo-Alonso, A. Chem. Commun. (Camb.) 2011, 47, 514-516.

(32) Bredas, J. L. Mater. Horiz. 2014, 1, 17-19.

(33) Saeed, M. A.; Le, H. T. M.; Miljanić, O. Š. Acc. Chem. Res. 2014, 47, 2074-2083.

(34) Martínez-Martínez, V.; Lim, J.; Bañuelos, J.; López-Arbeloa, I.; Miljanić, O. Š. Phys. Chem. Chem. Phys. 2013, 15, 18023-18029. 
(35) Zucchero, A. J.; McGrier, P. L.; Bunz, U. H. F. Acc. Chem. Res. 2010, 43, 397-408.

(36) Zucchero, A. J.; Wilson, J. N.; Bunz, U. H. F. J. Am. Chem. Soc. 2006, 128, 11872-11881.

(37) Row, T.N. G.; Parthasarathy, R.J.Am. Chem. Soc. 1981, 103,477-479.

(38) Antonijević, I. S.; Janjić, G. V.; Milčić, M. K.; Zarić, S. D. Cryst. Growth Des. 2016, 16, 632-639.

(39) van der Sluis, P.; Spek, A. L. Acta Crystallogr A 1990, 46, 194-201.

(40) Spek, A. L. Acta Crystallogr., Sect. D 2009, 65, 148-155.

(41) (a) Cyr, D. M.; Venkataraman, B.; Flynn, G. W. Chem. Mater. 1996, 8, 1600-1615. (b) Baumgärtner, K.; Meza-Chincha, A. L.; Dreuw, A.; Rominger, F.; Mastalerz, M. Angew. Chem. Int. Ed. 2016, 55, 15594-15598.

(42) Wood, P. A.; Borwick, S. J.; Watkin, D. J.; Motherwell, W. DS.; Allen, F. H. Acta Crystallogr., Sect. B 2008, 64, 393-396.

(43) Reddy, D. S.; Ovchinnikov, Y. E.; Shishkin, O. V.; Struchkov, Y. T.; Desiraju, G. R. J. Am. Chem. Soc. 1996, 118, 4085-4089.
(44) Wang, H.; Wang, W.; Jin, W. J. Chem. Rev. 2016, 116, 5072-5104.

(45) DeRose, P. C.; Early, E. A.; Kramer, G. W. Rev. Sci. Instrum. 2007, $78,033107$.

(46) Würth, C.; Grabolle, M.; Pauli, J.; Spieles, M.; Resch-Genger, U. Nat. Protoc. 2013, 8, 1535-1550.

(47) CrysAlisPro. Agilent Technologies; Oxford (UK); 2011-2014.

(48) Busing, W. R.; Levy, H. A. Acta Crystallogr. 1957, 10, 180-182.

(49) (a) Sheldrick, G. M., SHELXT, University of Göttingen and Bruker AXS GmbH, Karlsruhe (Germany), 2012-2014. (b) Ruf, M.; Noll, B. C.. Application Note SC-XRD 503, Bruker AXS GmbH, Karlsruhe (Germany), 2014. (c) Sheldrick, G. Acta Crystallogr., Sect. A 2015 , 71, 3-8.

(50) Burla, M. C.; Caliandro, R.; Camalli, M., et al. J. Appl. Cryst. 2007, 40, 609-613.

(51) (a) Sheldrick, G. M., SHELXL-20xx, University of Göttingen and Bruker AXS GmbH, Karlsruhe (Germany) 2012-2014. (b) Sheldrick, G. M. Acta Crystallogr., Sect. A 2008, 64, 112-122. 